Marquette University

e-Publications@Marquette

$1-1-1972$

\title{
A Metaphilosophical Reflection on the Aristotelian and Kantian Treatments of Time
}

Howard P. Kainz

Marquette University, howard.kainz@marquette.edu

Published version. The Thomist, Vol. 36, No. 1 (January 1972): 117-130. DOI. (C) 1972 Dominican Fathers Province of St. Joseph.Used with permission. 


\title{
A METAPHILOSOPHICAL REFLECTION ON THE ARISTOTELIAN AND KANTIAN TREAT- MENTS OF TIME
}

$\infty$

\begin{abstract}
1 CONSTANT DANGER which besets anyone who endeavors to compare the doctrine of two philosophers 11 on a single topic is that he might station himself at
\end{abstract} the attitude-perspective on one of the philosophers and criticize the other purely in terms of this vantage point. If criticizing one system or philosopher from the vantage point of another system or philosopher is not the prime reason for the seemingly irreconcilable rifts between philosophical schools, it at least contributes to these rifts. And very often, like the yankee in a foreign country, the philosophers must end up pointing at things or inventing terms on the spur of the moment, in order to make themselves understood, if possible, in lieu of the "language" of the strangers.

In this article I will, of course, try to avoid "negativity" in the sense of argumentativeness. Does this imply that I will attempt to view the doctrines of Kant and Aristotle from above, as it were? Perhaps, more precisely, from between the both of them. From this "position" I would like to set myself the task, not of locating logical identities, nor of finding mathematically exact congruences, but merely of observing general symmetries in the doctrines of the two men on a specific topic. The fact that one presupposes that such symmetry can be found might, of course, suggest an a priori bias towards oversimplification. But if he analyzes the writings of both philosophers and happens to notice a notable similarity of content represented under notably different forms, this would seem to be a case of "a posteriori observation" in the domain of philosophy. That is, the "observation" of attitudes and an attempt to draw unified conclusions from these observations. 
But if this be a valid approach, it would certainly be naive and undisciplined unless there were first a realization of the definite, solid differences in the viewpoints of the two authors in question. Therefore, before we examine the symmetries, mention should be made of the differences (for without the differences, symmetry would not be there, only identity):

Three major differences might be noted in the philosophies of Aristotle and Kant:

1) Aristotle set out to describe the physical world, going on the fundamental presupposition that the world was, indeed, intelligible. What was then necessary, upon this presupposition, was to make its potential intelligibility something actual, to bring its latent forms out into the open-in words, in concepts; and then, by a logical analysis of the properties of actual, intelligible form, to develop a metaphysics, ${ }^{1}$ which, once made explicit, would in turn lend definiteness and clarity to the physical world in a semi-autonomous way. But Kant's interests lay not so much in describing and delimiting the physical world, as in setting proper bounds to man's faculty of reason. Under impetus of the faith that he could best serve science and philosophy by accurately determining, once and for all, just what man could know and not know, and the various ways in which he could be related to the knowable, and the various ways in which he could be deceived as to the pseudoknowable, he set himself to accomplish a more "introverted" task. His starting point was reflection, and his goal the exploration of the faculty of reflection: reason. And therefore it is significant that, while Aristotle developed a system of categories of physical being, Kant developed a system of categories by means of which we must think.

2) In consonance with his concentration upon the domain of pure reason, Kant was primarily interested in solving the major problems raised by that ambiguous zone where subjective and objective meet; that is, the zone where intuitions

${ }^{1}$ Cf. Physics, II, 2, 194b; I, 9, 192a. 
are unified in concepts, or where ideas, rightly or wrongly, are given determinate phenomenal reference as content. In terms of his solutions to these problems, he also arrived at the corollary conclusion that we can know nothing about the positive reality of a substance behind phenomena, or a "thingin-itself," although we must presuppose some such reality because of the exigencies of our logical processes. Kant seems to think that Aristotle also held, at least implicitly, an analogous notion about matter, that is, that matter was a substratum which had to be presupposed for appearances and that the necessity which was ascribed to matter was a merely logical necessity. ${ }^{2}$ And such a notion may, indeed, be implicit in, e. g., the dictum of Aristotle that the "intelligible in act" is equivalent to the "intelligence in act." But explicitly, Aristotle always seems to treat of intelligible matter as something positive $^{3}$ and existing-in-itself. ${ }^{4}$

3) Kant, seeming to go on the presupposition that a philosophical system can only be complete and lucid when it is deduced in a manifestly unified way, looks upon Aristotle's system of categories as "defective." For Aristotle seems to have "merely picked them up as they came his way," ${ }^{5}$ not proceeding on the basis of any predetermined unifying method, but purporting to find by experience a complete set of objectively different types of things in the physical world. But Kant proposes for himself the task of overcoming the deficiencies of such a "haphazard" method by exploring the basis for all distinction and "objective" differentiation, namely, the mind's operations of judgment. And thus his system will give

${ }^{2}$ Critique of Pure Reason (N. Y.: St. Martin's Press, 1965), p. 516; (A 616; $B$ 644). All references to Kant's first critique in the body of this study will be to the 1781 and 1787 editions ( $A$ and $B$ editions). References to the $A$ and $B$ pagination are given in the Meiner German edition and in St. Martin's Press English Edition, both of which were used in the preparation of this article. Thus the $A$ and $B$ citations can be indirectly used to find texts in these two editions.

${ }^{8}$ Physics, I, 9, 192a; Aristotle sharply differentiates his position here from that of Plato, who looked upon matter as privation per se.

${ }^{4} \mathrm{Ibid}$., I, 6, 190a; also I, 9, 192a.

${ }^{5}$ Critique of Pure Reason, p. 114; Meiner ed., S. 119 (A 81; B 107). 
rise to a priori certainty and absolute comprehensivity, while Aristotle's would have only a tentative a posteriori certainty, i. e., a probability subject constantly to revision.

Thus Kant takes as his starting point the inexorable laws of logic, proceeds to describe the world of pure reason in terms of the categories of thought, and also gives special attention to the problematics of the subjective-objective no-man's-land of "appearance." Aristotle, on the other hand, seems to take physical facts as his starting point, and thereupon to describe the changing and unchanging aspects of the physical world, even striving to deduce a set of empirically comprehensive categories of objective types of physical being.

The recognition of these polar differences puts us in a position now to examine the "symmetries" in the doctrines of the two philosophers in regard to the subject of time.

\section{Synthetical Comparison of the Doctrines of Kant and Aristotle}

For purposes of clarity I will in the following section present. various pivotal notions of Kant in regard to time in the form of theses, and then elaborate on the corresponding "symmetrical" positions which seem to be implicit or explicit in Aristotle. Kant's theses, however, it should be noted, will be used only as a springboard for division of the subject under consideration and not as a criterion in terms of which judgment is passed on Aristotle.

1) The Subjective Aspect of Time:

THESIS: TIME IS A SUBJECTIVE FORM A PRIORI WHICH CANNOT BE THOUGHT OF AS ABSENT AND WHICH SUPPLIES THE APODEICTIC CONDITIONS FOR ALL RELATIONS OF CONTRADICTORILY OPPOSED PREDICATES IN SCIENCES OF MOTION AND ALTERATION WITHOUT GOING SO FAR AS TO GIVE THEM THE DETERMINATE UNITY OF A CONCEPT. (Critique of Pure Reason, A 31, B 46)

Aristotle does not say explicitly that time is a fundamentally subjective notion. He does, however, raise the question as 
to whether there could be such a thing as time in the absence of a human subject, i. e., a knowing soul. ${ }^{6}$ And he comes to the conclusion that time in such a case would exist as measurable ${ }^{?}$ (i. e., as potential) within motion, provided that motion itself could be said to exist under such conditions. Such a hypothetical conclusion, although it does imply that time under such conditions would probably be nothing actual, ${ }^{8}$ nevertheless does not opt for any preeminence of the "subjective" nature of time, especially in the Aristotelian framework, where the potential and the empirical are not prejudged for epistemological reasons to be less important than the actual and the a priori. But we can say that Aristotle recognizes the fact that time is quite subjective in nature, without going so far (as did Kant) to emphasize the subjective over the objective aspect.

Likewise, Aristotle gives us an indication that time in its subjective aspect is not a determinate concept (universal "form "), since the formation of all intellectual concepts must, according to him, take place outside of time. ${ }^{9}$ And without saying that it is a "form of sensibility" he does indicate that it is applicable only to a special sphere of existence, i. e., the realm of passing phenomena, of physical transmutation.

2) Its Foundation in Internal Perception:

THESIS: TIME IS A MOST GENERAL INNER DETERMINATION WHICH WE GIVE TO ALL REPRESENTATIONS AND IS INDEED THE RESULT OF THE SUCCESSION OF THESE REPRESENTATIONS BEING INTIMATELY APPROPRIATED THROUGH THE EMPIRICAL SELF OF CONSCIOUSNESS. (Critique of Pure Reason; ${ }^{10}$ A 33, B 49 )

The fact that our awareness of time is somehow linked up with our perception of the empirical processes or motions of

-Physics IV, 14, 223a.

${ }^{7}$ Cf. Randall, Aristotle (N. Y.: Columbia University, 1960), p. 202.

${ }^{8}$ Cf. Copleston, A History of Philosophy (N. Y.: Doubleday Image, 1962), Vol. 6, Part II, p .65.

${ }^{\circ}$ Cf: Mure, Aristotle, p. 214.

${ }^{10}$ Cf. also Collins, History of Modern European Philosophy (Milwaukee: Bruce, 1961), p. 481. 
our consciousness is recognized in a negative way by Aristotle when he states that when we are unconscious in sleep, etc., time " ceases" with respect to us." He puts the matter in a more positive way when he says that, in a completely dark room, we garner the perception of the passage of time precisely by noticing the movements of our own mind. ${ }^{12}$ The necessary and sufficient condition for our subjective ascription of time to events would seem, then, to lie in some minimal awareness of the alterations in our phenomenal self, through proprioception.

But again, whereas in Kant such an inner determination is described as a (subjective) form of sensibility, in Aristotle it is referred to as a "common sensible" (i.e., an objective type of sensible form), which results ultimately from the perception of alteration as a subjective process. ${ }^{13}$

3) Its Interconnection with Space:

THESIS: TIME, AS THE IMMEDIATE CONDITION OF INNER APPEARANCES, IS ALSO MEDIATELY THE CONDITION FOR OUTER (SPATIAL) APPEARANCES AND THUS SUPPLIES THE GENERAL FORM OR CONTEXT IN TERMS OF WHICH ALL APPEARANCE WHATSOEVER MUST BE PERCEIVED. (Critique of Pure Reason, A 34, B 50)

Aristotle does not, of course, stress the a priori character of time. But in consonance with his more " empirical" point of view, he does point out a definite and intimate connection of space (the potential serial infinity of continuous magnitude) ${ }^{14}$ and time (the potential measurability, or numerability, of spatial motion). We are speaking here, of course, of time as a "material" numberable, and not as the formal enumeration.

${ }^{11}$ Physics, IV, 11, 218b.

${ }^{12}$ Ibid., IV, 11, 219a.

${ }^{13} \mathrm{Cf}$. Mure, Aristotle (London: Benn, 1932), pp. 110, 111, who says, "[the perception of alteration] is thus a psychical miniature which enables us to gauge an external magnitude or duration, and the implication is that we compare the two terms and infer the outer from the inner." (He bases this conclusion on De Anima, III, 2, 426b, and II, 9, 421a; on Physies, IV, 11, 218b, and on Mem. et Remin., 2, 452b.)

${ }^{14}$ Cf. Ross, Aristotle (London: Methuen, 1949), p. 84. 
And it is with regard to time in this connotation that Aristotle says,

What is moved is moved from something to something, and all magnitude is continuous. Therefore the movement goes with the magnitude. Because the magnitude is continuous, the movement too must be continuous, and if the movement, then the time. ${ }^{15}$

Movement-in-space is thus a kind of " middle term " between space and time. The movement takes on the character of the continuous extensivity which supplies its material condition. And just as the continuous extensivity is divisible ad infinitum, so also the movement which is founded upon it is numerable ad infinitum. And it is precisely the numerability of motion that gives it the material character of time. ${ }^{16}$ Time is thus, in this sense, a new potentiality which is discerned within continuous motion, i. e., a latent attribute subject to perception and intellectual actualization by a human subject:

Time ... is continuous since it is an attribute of what is continuous [that is, motion]. ${ }^{17}$

As Ross puts it, the multiple, spatially perceptible events in the world are capable of taking on the attribute of "time," insofar as a single character of " nowness" can be attached to the multiplicity of them. And this attribution of "nowness" is indeed possible, insofar as each numerically single body is passing through a succession of points (geographical points, points of qualitative degree, or points of measurable size) which is capable of coinciding with the succession of points of movement of other bodies. ${ }^{18}$

In summary, we can say that, for Kant, space was inseparably interconnected with time (the formal a priori condition of space); for Aristotle, on the other hand, time is inseparably interconnected with space (the material substratum of time).

\footnotetext{
${ }^{15}$ Physics, IV, 11, 219a.

${ }^{18}$ Ibid., IV, 11, 219b; 220a.

${ }^{17}$ Ibid., IV, 11, 220a.

${ }^{18}$ Cf. Ross, Aristotle, p. 90.
} 


\section{4) Its Infinity:}

THESIS: TIME IS INFINITE AS AN INDEFINITE REPRESENTATION (C.P.R., A 32, B 48) PRIOR TO THE DISCRETE ARITHMETICAL NUMBERING OF APPEARANCES (Prologomena, para. 9 and 10)-SUCH THAT IT CAN BE RENDERED PRECISELY QUANTITATIVE ONLY THROUGH THE "AXIOMS OF INTUITION" OF THE UNDERSTANDING. (C. P. R., A 162, B 203) IT IS ALSO “ETERNAL," AS A COSMOLOGICAL IDEA. (C. $P . R$, A $426, \mathrm{~B} 454$ )

To say that time is "infinite" and that it is "eternal" is much the same thing, except that the former term refers mainly to time's formal indeterminacy, while the latter term refers primarily to the deficiency of precise limits in its cosmic content (the series of appearances or events in the world).

Aristotle, as Kant, comes to the conclusion that time is both infinite and etermal. But by a quite different procedure.

There is no such thing as an actual infinity in any kind of magnitude, according to Aristotle. ${ }^{19}$ But we can discern potential infinities with regard to space, number, and time. Space is potentially infinite insofar as it is divisible according to an infinite convergent series; number, insofar as it is augmentable according to an infinite divergent series. Time, on the other hand, is infinite in both ways, i. e., infinitely divisible in that it has a continuum of spatial magnitude as its bedrock of content ${ }^{20}$ and infinitely augmentable in that it is, formally speaking, an active numbering produced by the power of thought. ${ }^{21}$ Thus time is a potential infinity both materially, i. e., as continuous magnitude potentially divisible by " nows" which are always different, ${ }^{22}$ and formally, i. e., as a product of numbering thought, which is an "active" type of potentiality. ${ }^{23}$ But both the passive potentiality of the continuum and the active potentiality of thought are due to the subjective

\footnotetext{
${ }^{10}$ Physics, II, 6, 206a.

${ }^{20}$ Physics, III, 7, 207b; IV, 12, 220a.

${ }^{21}$ Ibid., III, 8, 208a. For the above general analysis of infinity in space, number, and time, cf. Ross, Aristotle, pp. 83-85.

${ }^{22}$ Cf. ibid., IV, 13, 22a; IV, 11, 219a.

${ }^{23}$ De Anima, II, 5, 417b.
} 
capacities of man, who does the dividing or the numbering. And so we might say that in both aspects of time it is the infinite variety of possible subjective variations of objective content that gives rise to the "potential infinitude" of time. Thus Aristotle and Kant, though widely divergent in their approaches, seem to be much at one in discerning the character of infinity in the subjective representation of time.

Likewise with Aristotle " eternity," or an eternal time, results when the formal attribute of temporality is attributed to the whole series of cosmological events in our experience. ${ }^{24}$ For when we consider this series, it is impossible to form the conception of an absolute beginning with no antecedent or an absolute end without succession, and so we are led by reductio $a d$ absurdum to posit an eternity of time. ${ }^{25}$ This is the same general line of reasoning which Kant follows in presenting the "antithesis" of an eternal world as an insoluble problem in the first antinomy of cosmological ideas. ${ }^{26}$

\section{5) Its Role in Statements of Existence:}

THESIS: TIME IS THE REGULATIVE MEANS BY WHICH THE UNDERSTANDING GIVES TO APPEARANCES THE FORM OF DETERMINATE EXISTENCE THROUGH THE “ANALOGIES OF EXPERIENCE" (Prologomena, para. 26; C.P.R., A 32, B 49) AND INDEED IS THE CONDITION FOR ALL PREDICATION OF EXISTENCE. (C. P. R., B 71)

It is Aristotle's doctrine that the sphere of time is co-terminous with the sphere of the physically existent and the physically possible, i. e., of things which are capable of some kind of physical transience and which are capable of being and not-being in succession. ${ }^{27}$ More precisely, time is the cause or condition of that type of existence of which alone we have experience-transient existence in this world. ${ }^{28}$ All of our thoughts must refer in some way to such existence-in-time.

\footnotetext{
${ }^{24}$ Physics, III, 6, 206a; IV, 13, 22b.

${ }^{25}$ Ibid., VIII, 1, passim.

${ }^{20}$ Critique of Pure Reason, p. $397 \mathrm{ff}$. (A 427, B 455).

${ }^{2 \tau}$ Physics, IV, 12, 221b; 222a.

${ }^{28}$ Ibid., IV, 12, 221b; IV, 13, 222b.
} 
As Aristotle puts it,

We cannot exercise the intellect on any object absolutely apart from the continuous, or apply it even to non-temporal things unless in connection with time. ${ }^{29}$

Thus, not only when we make a judgment such as " $\mathrm{x}$ exists" but also when we make a judgment of the general form " $\mathrm{x}$ is $y$ "-and even where $\mathrm{x}$ and/or $\mathrm{y}$ is (are) non-temporal ideas (s) or separate substance (s) - the judgment cannot be made without some reference to some experience definitely situated in time. And so also, if there be any " truth" in our judgments, this cannot obtain without some relationship to the continuum of time..$^{30}$

6) Time's Unification in and Through Consciousness:

THESIS: OUR INTUITION OF TIME, BY MEANS OF THE SCHEMATA OF THE IMAGINATION, (C. P. R., A 138, B 177) IS SUBORDINATED NATURALLY TO OUR UNITY OF APPRECEP. TION, WHICH IS THE PRIOR CONDITION FOR KNOWLEDGE OF THE EMPIRICAL IN GENERAL, (C. P. R., A 343, B 68, 401, 422) AND (IN THIS SUBORDINATE ROLE) GOVERNS THE APPLICATION OF THE CATEGORIES OF THE UNDERSTANDING TO THE WORLD OF APPEARANCE. (C.P. R., A 138, B 177)

In Metaph., IV, $6{ }^{31}$ Aristotle criticizes Heraclitus and other epistemological relativists who say that all true being and beings are merely their own contingent and relative perceptions of things. In doing this, argues Aristotle, they imply that they themselves have no unity of being, but are, rather, discrete multiplicities. For if all objects of knowledge differ only relationally, i. e., insofar as they have a different relationship to the knower, then the knower himself must be a different correspondent term for every object which is related to him (just as an object which is double, and triple, and equal can only be so insofar as it is related to a different term under each of these aspects).

${ }^{20}$ De Mem. et Remin., 450a.

${ }^{30}$ Cf. Metaph., IX, 9, 1051b; also, De Anima, III, 6, 430a.

${ }^{31}$ Cf. loc. cit., $1011 b$. 
Thus although Aristotle does not point explicitly to any " unity of apperception" as a positive attribute of intellective consciousness, he does take such unity for granted in arguing against those who by their own doctrines are forced to conceive consciousness as a series of discrete, non-related states or motions. And since time is perceived in a primary way through the motions of one's own consciousness, it would be implied that it is subsumed in a immediate manner into the higher unity of intellective consciousness, for the purpose of rendering judgments of physical reality possible.

7) Its All-Inclusive Unity:

THESIS: ALTHOUGH WE CAN THINK DISTINCT TIMES IN SUCCESSION, ALL THESE TIMES ARE MERELY DETERMINATIONS OF ONE ALL-PERVASIVE, ALL-INCLUSIVE, GENERAL TIME, WHICH IS NOT A DETERMINATE ABSTRACT CONCEPT BUT AN INDETERMINATE FORMAL CONDITION OF REFERENCE TO THE PHENOMENAL WORLD. (C.P. R., A 32, B 47)

As we might expect, Aristotle attributes such all-inclusive unity to time as a quasi-material substratum rather than as a formal condition:

According to him, time as numerable-i.e., as the continuum of motion which is measurable ${ }^{32}$-is par excellence the cyclical motion of the heavenly spheres, which proceed most regularly, uniformly, predictably. ${ }^{33}$ But since there is a greater time which measures all time and all existents, ${ }^{34}$ we might reasonably say that the motion of the outermost sphere would be the single numerable continuum giving rise to all numerability and time in subordinate spheres. And, indeed, this one recurring outer motion would be the primordial continuum giving rise to the possibility of all actual time as the numbering of motion..$^{35}$ As Randall says, the eternal circular motion of the outer sphere of the universe is

\footnotetext{
${ }^{\text {s2 }}$ Physics, IV, 12, 221a.

${ }^{33}$ Ibid., IV, 14, 223b.

${ }^{34}$ Ibid., IV, 12, 221b.

${ }^{35}$ Physics, IV, 13, 292a.
} 
the common frame of reference for all temporal measurement, since its number is best known, i. e., as primarily conditioning all regularity whatsoever. ${ }^{36}$

Thus, just as Kant from his idealistic vantage point sees time as a unique form of sensibility containing in an indeterminate way all particular, determinate times, so also Aristotle, with a more objective orientation, sees it primarily as an attribute or inherent possibility of the unique " outermost sphere" of the universe.

8) Its Inapplicability to any "Transcendent" World:

THESIS: "ETERNITY" AS A PURELY TRANSCENDENTAL IDEA IS WITHOUT REAL INTUITIVELY-GIVEN CONTENT OR REFERENCE TO THE REALLY KNOWABLE WORLD OF TEMPORAL PHENOMENA. (C. P. R., A 641, B 669)

It should be noted that we are speaking here not of "eternal time " as a cosmological idea but of etemity as an anthropomophically-conceived attribute of some metaphysical " necessary being" or some metaphysical world. As such, it is a merely negative concept and denotes the timelessness of a necessary being, or of an ens realissimum, or of a separate substance, or of an idea, or of a "moment" as created arbitrarily by a numbering mind, or of an eternal principle whose denial results in self-contradiction.

Aristotle states quite clearly that time neither measures nor affects any such sphere of eternity or anything whose nature is eternal in this strict, absolute sense of the word. ${ }^{37}$ Time is validly applicable only to the sphere of physical, corporeal transience. It ceases to apply just short of the boundaries of thought and the entities of thought. ${ }^{38}$

Aristotle differs from Kant, of course, in that he posits a metaphysical world of the prime mover and the unmoved

${ }^{36}$ Randall, Aristotle, p. 203.

${ }^{37}$ Physics, IV, 12, 221a; 221b.

${ }^{38}$ It should be noted, however, that, while time does not apply to these boundaries, it is still the material means and context out of which such "boundaries" are formulated. (Cf. sect. 5, supra) 
movers and the souls of the primary celestial self-movers in each sphere ${ }^{39}$ and the separable "active" intelligence in man; ${ }^{40}$ and in that he speaks of such "eternal" things as of real entities. Kant, on the other hand, only admits the possibility of some such things, and the practical fact that we must sometimes presuppose them, in order to give greater unity and completeness to our knowledge. But whether such a "metaphysical" world be conceived as an actuality or as a bare, empty possibility, it is granted by both philosophers that time will be completely inapplicable to it. Neither of them will admit of a monistic structure in which time and eternity can somehow be identical.

\section{Conclusion}

Just as two persons who begin at different sides of a room would be apt to apply the terms, "right," "left," "front," and "behind" in different ways to the same things, it would seem that the different starting points of Kant and Aristotle-as mentioned in the introduction-have led them to describe certain selfsame attributes of time in different ways. Thus, for instance, Kant sees time as a formal unity, while Aristotle sees it as a unity in its material substratum of continuous extension; both see it as interconnected with space, but Aristotle, unlike Kant, takes space as the starting point for this insight; both see it as an infinity, but Aristotle designates it a potential infinity of that which is actual and determinate, while Kant designates it an actual infinity of that which is of its very nature incomplete and contentless (the a priori form of sensibility); and so forth.

One of the most notable things that can be discerned in the unity-in-difference which prevails between Kant and Aristotle on the subject of time is that the former is almost always speaking about it in its formal aspect, while the latter is

\footnotetext{
${ }^{38}$ Provided that such souls are taken as distinct in existence from the " unmoved mover" of each sphere. It is not clear whether Aristotle can be interpreted in this way.

${ }^{\circ}$ De Anima, III, 5, 430A.
} 
very often merely referring to it in its material or potential aspect. Once this is understood, we have the key to a good number of moot points which seem at first encounter to represent widely divergent opinions or solutions but then upon further examination are found to be most conveniently reducible to poles of attitudinal bias.

Howard P. KaInz

Marquette University

Milwaukee, Wisconsin 